\title{
Perspectives on assisted dying
}

\author{
David Badcott $\cdot$ Fuat S. Oduncu
}

Published online: 28 July 2010

(C) Springer Science+Business Media B.V. 2010

Wrongfully prolonged life can be as tragic an error as wrongfully terminated life. In life's unhappier end games there can be no 'safe side'

to err on.

Joel Feinberg. Harm to self, p. 370.

There is no shortage of collections or individual papers on assisted dying and other end-of-life issues. They have been a regular feature of ethical evaluation and debate for many years. The fact that such papers continue to be published is testimony not only to a continuing awareness of professional and lay concerns, but also to changing circumstances, particularly regarding some measure of shift in legal constraints or public opinion. Yet, above all, the continuing debate reflects both a failure to convincingly win the argument one way or the other, and highlights the persistence of seemingly intractable opposing views, unlikely to be easily swayed.

Most of the group of papers in this themed section developed from presentations during a seminar held at the conference of the European Society for Philosophy, Medicine and Health Care at the University of Tartu in August 2008. None of the papers sets out to offer a detailed ethical critique of reasons for legalising assisted dying or indeed to justify its prohibition - the literature abounds with theseand there is no intentional common thread linking

\section{Badcott $(\bowtie)$}

Centre for Applied Ethics, Cardiff University, Humanities Building, Colum Drive, Cardiff CF10 3EU, UK e-mail: badcottd@cf.ac.uk

\section{F. S. Oduncu}

Klinikum der Universität München, Medizinische

Klinik - Campus Innenstadt, Hämatologie und Onkologie,

Ziemssenstrasse 1, 80336 Munich, Germany

e-mail: Fuat.Oduncu@med.uni-muenchen.de individual contributions other than that they offer a perspective on some important aspects of the debate. Two of the papers focus on national experiences of end-of-life issues in either The Netherlands (Kimsma (2010)) or Germany (Oduncu and Sahm (2010)), whilst Schicktanz and colleagues (2010) compare the differences in approach to end-of-life decisions in Germany and Israel.

Kimsma describes the evolution of the Dutch experience of euthanasia over many years, covering the legal background, procedural requirements and the system of firm regulatory and administrative controls. But the key focus of his paper is to highlight the psychological and ethicalphilosophical conflicts experienced by physicians and others when confronted with a request to end a life. These conflicts, in part have an emotional basis, but also stem from a real need to identify closely with a suffering patient, in order to recognise the authenticity and authority of that patient's preference that his/her life should be ended. The author is conscious that (a) the process of euthanasia or assisted dying means overriding a fundamental aversion to ending innocent human life and (b) at the same time that the normal and overwhelming therapeutic or palliative obligations are rather disturbingly set aside.

It could perhaps be argued that the Dutch attitude to end-of-life issues reflects if not wholehearted public acceptance, at least demonstrates an increasing and rather settled tolerance, related to cultural inclination. Indeed, Schicktanz and Shalev (2010) have considered whether cultural differences and social conceptions might influence the national acceptability and legality of end-of-life decisions. Although their study is limited to just two countries, the authors identify both similarities and key differences in the recommendations of the respective German and Israeli national expert ethics committees. Concerning the latter, the Israeli approach is firmly in line with a deep-seated 
religious respect for the sanctity of life, whilst the German emphasis is much more dependent on liberal or cultural considerations of personal autonomy. Yet the authors detect some drawing back from both approaches. In Israel, the Steinberg Committee's proposal highlighted pragmatic opportunities in the distinction between (life-maintaining/ prolonging) treatment as an act, and such treatments viewed as related sequences. Delivering 'timer-controlled" treatment would permit an opportunity for patients to exercise their autonomy in advance by making clear their wishes that a timer should not be re-set. By contrast in Germany, there is evidence that not all official bodies favour a strengthening of respect for patient autonomy with regard to advance directives.

Although members of the public have been encouraged to contribute to the debate on end-of-life issues, active voluntary euthanasia remains illegal under the German Criminal Code and doctor participation in suicide is punishable by law. In their review of the medical and legal context of end-of-life issues in Germany, Oduncu and Sahm firmly reject permissive and self-deterministic policies of euthanasia and assisted dying that, as they see it, would deny the established tradition of due patient care. But whilst the authors emphasise the importance of seeking to harmonise all medical decisions in accordance with the patient's will and ascertaining their views in advance (so that these may be taken into account when and if a patient lacks competence), they oppose the deliberate ending of life. They favour instead a palliative approach of compassionate and virtuous doctor-cared dying, a position that, they assert, is not incompatible with withholding or withdrawing treatments that needlessly prolong the onset of death or the possibility of alleviating suffering at the unavoidable cost of shortening life.

Three other papers deal with arguably somewhat more peripheral perspectives on end-of-life issues. Stempsey (2010) explores the role of religious belief in public debate about physician-assisted dying (PAS); Badcott (2010) considers the influence of public opinion on assisted dying in an increasingly diverse society; and Holm (2010) suggests that agreeing to disagree with respect to end-of-life issues should be recognised as a deceptively complex compromise with potentially unstable consequences.

Most people would probably agree that religion has had and for many continues to exert a significant influence on their cultural and moral attitudes particularly concerning the end of life. But, as Stempsey (2010) points out, despite its undeniable importance, there is, nevertheless a deepseated ambivalence about the proper role of religion in public discourse and often a palpable reluctance to use religious terminology or build religious concepts into legislation or public discussion. Politicians and others when faced with the unenviable problem of deciding how to reflect religious beliefs which themselves can be diverse and conflicting, often elect to take a safer, secular option, expressed in the language of public reason. Yet, according to Stempsey, the very nature of abortion, assisted suicide and euthanasia unavoidably introduces religion into the public sphere and our disagreements about these matters should not lead us to deny the religious element inherent in dying.

Taking a Habermasian line, Stempsey argues that basing support for PAS solely on autonomous choice by individuals ignores the vital social dimension, which for religious people may be central and irreducible to a more general conception of community. Even in an increasingly secular society, religion-directly or indirectly-is still an important component in the lives of many people, particularly when approaching the end of that life. In view of this importance, the religious dimension should not be sidelined in public political discussions about PAS.

Public opinion is often used or quoted as an indicator of support for a particular position concerning issues of major importance. Newspapers and other media frequently refer to surveys of public opinion to give prominence to an issue they wish to promote and "end of life" considerations is one such topic. And yet "public opinion" is at best a crude measure, based on samples with an imperfect relationship to the overall population. In his paper, Badcott (2010) explores the nature of public opinion and considers the possibility that recent immigrants from other European countries, and beyond, many of whom have a strong religious background may have a significant influence on attitudes to assisted suicide. But the relationship between "public opinion" and representative democracy is seldom if ever clear cut. And Badcott argues any change in the law that would allow PAS is dependent on the vagaries of the climate of opinion within the Houses of Parliament and an uncertain and largely unpredictable relationship with public opinion. The volatile nature of the influence of religious observance of the UK population is therefore likely to be subtle.

Profound disagreements about end of life matters are undeniable. Irrespective of whether euthanasia and assisted dying are legalised or not, there will inevitably be a substantial and sometimes majority of those who oppose the official standpoint. Faced with such diametrically opposing views, it is tempting and understandable to say, "We will just have to agree to disagree". Holm's (2010) paper provides an important critique of what has become something of a commonplace cliché. Using some of the familiar discussions about legalisation of active, voluntary euthanasia performed by medical doctors as a template, Holm carefully dissects many of the important though nevertheless frequently overlooked implications of "agreeing to disagree". Far from being a stable accommodation of 
opposing views which may be a precursor to some measure of (eventual and tangible) agreement, at best "agreeing to disagree" often represents no more than a standoff of firmly entrenched positions, the status quo in sheep's clothing.

The final paper in this group on end of life issues is of a markedly different nature to the others. Few of us whether practitioners in those areas where the end of life of patients is part of our professional practice or indeed those philosophers and others who write on such matters are ever faced with the profound challenges that occur when the life of a close relative or friend is suddenly and catastrophically compromised. Even fewer would find the strength and determination to describe the progression of their experiences and thoughts over time. But Battin (2010) whose husband Brooke was paralysed following a serious bicycle accident in Autumn 2008 has done just that. In presenting a very personal account, Peggy provides a singularly moving and graphic summary of the many challenges and ups and downs of the situation in which she and Brooke found themselves. But more than that, she has bravely given an analysis of the influence that Brooke's accident has had on her philosophical thinking and stance concerning end of life issues. Her overall attitude to PAS has not changed markedly_-she has been an unwavering supporter for legalization of PAS for over 30 years-but she is now personally aware of the profound complexity of the individual case and the immense difficulty of achieving a workable and humane social policy on PAS.

Perhaps one aspect of these papers concerning end of life issues is clearer than most others. It is apparent in all of the papers to a greater or lesser extent, and that is, that despite goodwill on all sides, if indeed such is the case, there is "little prospect that we will come to agreement about whether physicians should be allowed to assist in bringing about the death of patients" (Stempsey (2010)). A philosopher, the late Stuart Hampshire writing in 1989 put his finger on the even more unpalatable but perceptive conclusion concerning moral matters in general: "The assumption has been that, from a moral point of view, the bedrock of human nature is to be found in self-evident and unavoidable beliefs. But after every attempt the alleged unavoidable beliefs are shown to be either vacuous or, if substantial, dubious, and at least very far from being unavoidable. We should look in society not for consensus, but for ineliminable and acceptable conflicts, and for rationally controlled hostilities, as the normal condition of mankind; not only normal, but also the best condition of mankind from the moral point of view, both between states and within states". Such being the case, philosophers and practitioners are likely to be writing about PAS and end of life issues for the foreseeable future and perhaps even the long term. We should not "agree to disagree", but try to identify those ineliminable, and acceptable conflicts at least as a means of providing better clarity of the issues and arguments, and work toward developing a mutually sympathetic understanding of opposing views.

\section{References}

Badcott, D. 2010. Assisted dying: the influence of public opinion in an increasingly diverse society. Medicine Health Care and Philosophy 13. doi:10.1007/s11019-010-9268-x.

Battin, M.P. 2010. The irony of supporting physician-assisted suicide: a personal account. Medicine Health Care and Philosophy 13. doi:10.1007/s11019-010-9274-z.

Feinberg, J. 1989. Harm to self (Moral Limits of the Criminal law), paperback ed. New York: Oxford University Press.

Hampshire, S. 1989. Innocence and experience. London: Penguin Books.

Holm, S. 2010. Euthanasia: agreeing to disagree. Medicine Health Care and Philosophy 13. doi:10.1007/s11019-010-9264-1.

Kimsma, G.K. 2010. Death by request in the Netherlands: facts, the legal context and effects on physicians, patients and families. Medicine Health Care and Philosophy 13. doi:10.1007/s11019010-9265-0.

Oduncu, F., and S. Sahm. 2010. Doctor-cared dying instead of physician-assisted suicide: a perspective from Germany. Medicine Health Care and Philosophy 13. doi:10.1007/s11019-0109266-z.

Schicktanz, S., Raz, A., and C. Shalev. 2010. The cultural context of patient's autonomy and doctor's duty: passive euthanasia and advance directives in Germany and Israel. Medicine Health Care and Philosophy 13. doi:10.1007/s11019-010-9262-3.

Stempsey, T.W. 2010. The role of religion in the debate about physician-assisted dying. Medicine Health Care and Philosophy 13. doi:10.1007/s11019-010-9267-y. 